\title{
PELAKSANAAN MANUAL TRAKSI DAN ISOMETRIK EXERCISE TERHADAP PENINGKATAN AKTIVITAS FUNGSIONAL PADA PENDERITA OSTEOARTHRITIS KNEE DI RUMAH SAKIT GRANDMED LUBUK PAKAM
}

\section{Sabirin Berampu ${ }^{1 *}$, Timbul Siahaan ${ }^{1}$, Isidorus Jehaman ${ }^{1}$, Samuel Ginting $^{1}$, Duwi Mekarsari ${ }^{1}$}

\author{
${ }^{1}$ Program Studi Fisioterpi , Institut Kesehatan Medistra Lubuk Pakam \\ Program Studi Keperawatan S1, Institut Kesehatan Medistra Lubuk Pakam \\ JIn. Sudirman No.38 Lubuk Pakam, Kabupaten Deli Serdang, \\ Sumatera Utara - Indonesia \\ *email korespondensi author: sabirinberampu@gmail.com
}

DOI $10.35451 / j p k . v 1 i 1.765$

\begin{abstract}
Abstrak
Osteoarthritis merupakan suatu gangguan degeneratif kronik yang terutama mempengaruhi kartilago artikular sendi sinovial, dan pada akhirnya terjadi remodeling tulang dan pertumbuhan berlebih (taji) pada batas sendi. Juga terjadi progresi penebalan sinovial dan kapsula serta efusi sendi. Gangguan akibat osteoartritis menyebabkan aktivitas terbatas dan kemampuan hidup terbatas. Ketika tulang rawan di sendi hancur, tulang di bawah tulang rawan menjadi lebih tebal, dan pada multiple sclerosis, jaringan tulang sendi tumbuh, menekan kapsul sendi, yang dapat menyebabkan peradangan dan kelemahan. Otot-otot yang menghubungkan persendian. Penelitian ini bertujuan untuk mengetahui pengaruh traksi pasif dan latihan isometrik pada pasien osteoarthritis lutut di RS Grandmed Lubuk Pakam. Penggunaan tes semi empiris oleh kelompok pretest sebanyak 19 responden. Pengukuran Aktivitas Fungsional dengan Skala Jette, dengan menggunakan analisis paired sample t-test. Ada pengaruh yang signifikan aktivitas fungsional sebelum dan sesudah. uji hipotesa dengan uji paired sampel t-test diperoleh dengan hasil $p$-value $<a(0.001<0,05)$. Ada Pengaruh Manual Traksi dan Isometric Exercise Terhadap Peningkatan Aktivitas Fungsional Pada Penderita Osteoarthritis Knee Di Rumah Sakit Grandmed Lubuk Pakam.Peneliti menyarankan agar peneliti selanjutnya menambahkan jumlah sampel dan waktu yang lebih lama agar hasil yang didapatkan lebih maksimal.
\end{abstract}

Kata Kunci : Osteoarthritis Knee, Manual Traksi, Isometric Exercise, Aktivitas Fungsional

\begin{abstract}
Osteoarthritis is a chronic degenerative disorder that primarily affects the articular cartilage of the synovial joint, and ultimately bone and remodeling (spurs) at the joint boundary occur. Synovial thickening and capsule progression and joint effusion also occur. Disorders due to Osteoarthritis cause limited activity and limited ability in activities. Because, damage to the cartilage (cartilage) of the joint, so that the thickness of the subcondral bone increases, sclerosis of the bone plate, the growth of osteophytes in the joints, can stretch the joint capsule, resulting in inflammation, and weakening of the muscles connecting the joints. This study aimed to determine the effect of Manual Traction and Isometric Exercise in patients with Knee Osteoarthritis at Grandmed Lubuk Pakam Hospital. Using quasi experiments with one group pretest posttest with a sample of 19 respondents. Measurement of Functional Activity with Jette Scale, using paired sample t-test analysis. There is a significant influence on
\end{abstract}


Received: 18 June 2021 :: Accepted: 26 June 2021 :: Published: 30 June 2021

functional activities before and after. hypothesis test by paired sample $t$-test obtained with the results of $p$-value $<a(0.001<0.05)$. There is the Effect of Manual Traction and Isometric Exercise on Functional Activity Enhancement in Patients with Knee Osteoarthritis at Grandmed Lubuk Pakam Hospital. Researchers suggest that the next researcher add a number of samples and a longer time so that the results obtained are more maximal.

Keywords: Osteoarthritis Knee, Manual Traction, Isometric Exercise, Functional Activity.

\section{Pendahuluan}

Osteoarthritis adalah masalah kesehatan utama untuk sendi lutut, dan osteoarthritis dapat merusak sendi lainnya. Keluhan terbesar pasien osteoarthritis lutut adalah nyeri pada bagian tengah lutut, yang membatasi rentang gerak dan aktivitas fungsional. Berdasarkan data World Health Organization (WHO) pada tahun 2017, Osteoarthritis diketahui bahwa diderita oleh 151 juta jiwa menderita Osteoarthritis di dunia hingga 24 juta jiwa di kawasan Asia Tenggara (Delima, 2017).

Di dunia terutama Inggris dan Wales mengatakan, sekitar 1,3 hingga 1,75 juta orang banyak mengalami gejala Osteoarthritis (Ismaningsih, 2018). Di Amerika, Osteoarthritis panggul $7,4 \%$, dengan prevalensi lakilaki $6.7 \%$ dan lebih banyak $8 \%$. Sedangkan Osteoarthritis Knee 12,2 \% , wanita lebih banyak $14,9 \%$ di bandingkan pria $8,7 \%$ yang terkena Ostearthritis Knee (Theresia, 2015). Secara keseluruhan, dari sekitar 10$15 \%$ orang dewasa lebih dari 60 tahun banyak menderita Osteoarthritis. Asia Tenggara di Negara Thailand 25,4\% pada perempuan dan $19,8 \%$ pada lakilaki. Dampak ekonomi, psikologi dari Osteoarthritis sangat besar, tidak hanya untuk penderita, tetapi juga keluarga dan lingkungan (Mayandri,2017). Di Norwegia angka prevalensi Ostearthritis $12,8 \%$ dan lebih tinggi dibandingkan perempuan ( $14,7 \%$ dibandingkan laki -laki (10,5\%) ( Anisa, 2015). Penyebab stabilitas tulang dan sendi di Cina berusia lebih dari 40 tahun. (Ayling, 2017). Di Indonesia, prevalensi Osteoartritis mencapai 5\% pada usia $<40$ tahun, 30\% pada usia
40-60 tahun, dan $65 \%$ pada usia $>61$ tahun.Untuk Osteorthritis knee prevalensinya cukup tinggi yaitu $15,5 \%$ pada pria dan $12,7 \%$ pada wanita.(Bunga, 2015). Kementrian Kesehatan Republik Indonesia pada tahun 2018 berhasil memetakan jumlah penderita Osteoarthritis Hasil $11,5 \%$ lebih orang Indonesia menderita Osteoarthrits Artinya, pada setiap penduduk Indonesia terdapat satu orang penderita Osteoarthritis. Prevalensi Penyakit sendi berdasarkan diagnosa tenaga kesehatan di Indonesia $11,9 \%$ dan berdasarkan gejala $24,7 \%$. Prevalensi berdasarkan di Bali 19.3\% sedangkan berdasarkan gejala tertinggi di Nusa Tenggara Timur 33,1\%, Jawa Barat 32,1\% DKI jakarta 21,8 \%.Jika dilihat karakteristik umur $\geq 75$ tahun $(54,8 \%)$, Penderita wanita juga lebih banyak $(27,5 \%)$ dibandingkan dengan pria (21,8\%) (Bunga, 2015).Dinas Kesehatan Provinsi sumatera Utara tahun 2013 menyebutkan bahwa gangguan Osteoarthritis menempati urutan ke-6 dari 10 penyakit terbanyak yang dilaporkan dari keseluruhan puskesmas sumatera utara (Mayandari, 2014).

Peningkatan populasi lansia penyakit degeneratif akan mengalami beberapa permasalahan dalam bidang masalah bagi kesehatan. Osteoarthritis knee Penyakit degeneratif yang sering dialami lansia. Osteoarthritis menempati ke dua setelah hipertensi dengan prevalensi berdasarkan kelompok umur 55-64 tahun (45\%), 65 -74 tahun $(51,9 \%)$ dan $75+$ tahun $(54,8 \%)$. Penyakit sendi kronis yang paling umum dan sangat memberikan peran untuk kecacatan, dan penurunan aktifitas fungsional yang 
Received: 18 June 2021 :: Accepted: 26 June 2021 :: Published: 30 June 2021

dapat mengakibatkan lansia mengalami penurunan aktifitas fungsional dalam kehidupan sehari-harinya merupakan salah satu penyakit Osteoarthritis (Gay,et al, 2016).

Peneliti (Shahnawaz, 2014) menyatakan bahwa efek dari Isometrik Exercise adanya perubahan yang signifikan terhadap kekuatan paha depan menunjukkan perbedaan. Hasil penelitian mendapatkan hasil bahwa Traksi osilasi efektif dalam menurunkan nyeri dan dapat meningkatkan Aktivitas Fungsional pada Ostearthritis Knee (Junaidi, 2013).

Berdasarkan survei pendahuluan di Rumah Sakit Grandmed tercatat jumlah pasien fisioterapi pada tahun 2018 dengan sebanyak jumlah 7857 pasien di poli fisioterapi rumah sakit grandmed, sedangkan khusus pada pasien Osteoarthtritis Knee dari bulan Desember 2018 sampai dengan Maret 2019 sebanyak 320 pasien. Rerata pasien perbulannya 80 pasien kunjungan perbulan. Osteoarthtritis Knee merupakan penyakit dengan prevalensi sebanyak ke 2 di Rumah Sakit Grandmed. Oleh karena itu penulis tertarik untuk mengambil kasus Osteoarthritis Knee di Rumah Sakit Grandmed lubuk pakam.

\section{Metode}

Jenis metode penelitian adalah eksperimen (semi empiris) dengan menggunakan model desain sebelum uji kelompok. Artinya, setelah mengamati dan mengolah sampel sebelum diolah, dilakukan pengamatan ulang (Arikunto, 2012).Bagian rancangan pre-test dan post-test penelitian adalah sebagai berikut.

Pengukuran Osteoarthritis Knee:

\section{Pre Test \\ Perlakuan Post Test}

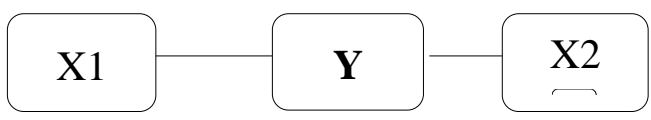

Keterangan :

Y: Perlakuan Manual Traksi Dan Isometric Exercise Pada Penderita Ostearthritis Knee
X1 : Skala fungsional sebelum dilakukan intervensi Manual Traksi dan Isometric Eexercise (Pre- Test).

Populasi pada penelitian ini adalah seluruh pasien Osteoarthritis Knee yang mempengaruhi kriteria insklusi di Rumah Sakit Grandmed Lubuk Pakam Tahun 2018 periode Januari sampai Desember sebanyak 240 orang, dengan rata-rata yang berkunjung dengan diagnosa Osteoarthritis Knee selama seminggu 20 orang.

Dengan teknik pengambilan sample : purposive sampling. Teknik purposive sampling dilakukan dengan cara memasukkan setiap pasien yang memenuhi kriteria inklusi dan eksklusi.

\section{Hasil dan Pembahasan}

Berdasarkan Pengumpulan data yg sudah dilakukan pada Rumah Sakit Grandmed Lubuk Pakam Tentang peningkatan kegiatan Fungsional dalam penderita Osteoarthritis Knee, maka pengolahan data sebelum data anugerah hegemoni Manual Traksi \& Isometric Exercise. Pada penelitian ini dapat dilihat pada tabel di bawah ini :

Tabel 3.1 Distribusi Nilai Peningkatan aktivitas fungsional sebelum intervensi Manual Traksi dan Isometric Exercise pada penderita Osteoarthritis Knee di Rumah Sakit Grandmed Lubuk Pakam

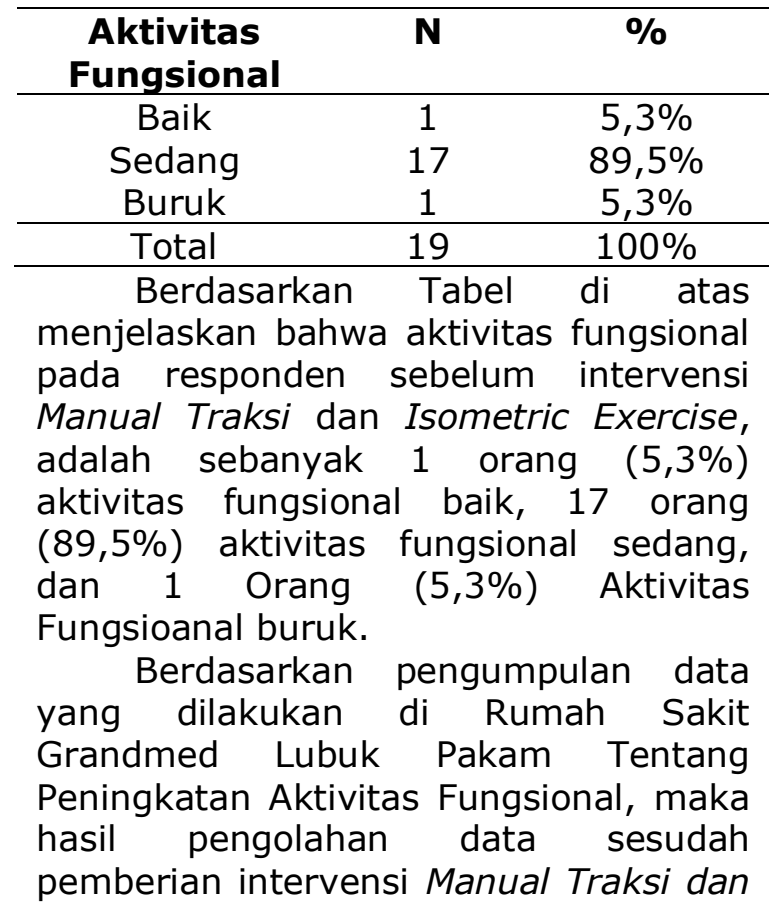


Received: 18 June 2021 :: Accepted: 26 June 2021 :: Published: 30 June 2021

Isometric Exercise .pada penelitian ini dapat dilihat pada tabel 4.2 di bawah ini

Tabel 3.2 Distribusi Nilai Peningkatan aktivitas fungsional sesudah Intervensi Manual Traksi dan Isometric Exercise pada penderita Osteoarthritis Knee di Rumah Sakit Grandmed Lubuk Pakam.

\begin{tabular}{ccc}
\hline $\begin{array}{c}\text { Aktivitas } \\
\text { Fungsional }\end{array}$ & $\mathbf{N}$ & $\mathbf{\%}$ \\
\hline Baik & 8 & $42,1 \%$ \\
Sedang & 11 & $57,9 \%$ \\
Buruk & 0 & $0 \%$ \\
\hline Total & 19 & $100 \%$ \\
\hline Berdasarkan & Tabel & menjelaskan
\end{tabular}

bahwa Aktifitas Fungsional pada responden sesudah intervensi Manual Traksi dan Isometric Exercise, adalah sebanyak 8 orang $(42,1 \%)$ aktivitas fungsional Baik, 11 orang (57,9\%) aktivitas fungsional Sedang dan 0 orang (0\%) Aktivitas Fungsional Buruk.

Teknik yang dpergunakan untuk menganalisis data yang didapat dari hasil penelitian ini adalah teknik uji paired sample t-test dengan taraf signifikan 95\% $(a=0.05)$. untuk mengetahui apakah ada pengaruh pemberian intervensi Manual Traksi dan Isometric Exercise terhadap peningkatan aktivitas fungsional pada penderita osteoarthritis knee di Rumah Sakit Grandmed Lubuk Pakam.

Berdasarkan hasil sebelum dilakukan pemberian Manual Traksi dan isometric Exercise Pada Penderita Osteoarthritis Knee di ketahui nilai ratarata aktivitas fungsional sebesar 22,58 dengan SD 4,635.sedangkan sesudah diberikan Manual Traksi dan isometric Exercise Pada Penderita Osteoarthritis Knee diketahui rata-rata aktivitas fungsional sebesar 18,00 dengan SD 4,655.

Hasil uji statistik diperoleh p-value $<$ a $(0.001<0,05)$ maka dapat disimpulkan bahwa ada pengaruh yang signinifikan antara aktivitas fungsional sebelum dan sesudah di berikan perlakuan Manual Traksi dan Isometric Exercise Terhadap peningkatan aktivitas fungsional pada penderita Osteoarthritis Knee Di Rumah Sakit Grandmed Lubuk Pakam Pakam. Maka dapat diambil keputusan bahwa ada pengaruh pemberian Manual Traksi dan Isometric
Exercise terhadap peningkatan aktivitas fungsional pada penderita Osteoarthritis Knee. Osteoarthritis Knee disebabkan menyempitnya celah sendi yang mengakibatkan nyeri dan keterbatan gerak sehingga menimbulkan penurunan kemampuan fungsioanal seperti berdiri,berjalan,jongkok dan naik turun tangga.

Hasil penelitian ini sesuai dengan penilitian dilakukan Junaidi, (2013) tentang Pengaruh Pemberian Terapi Osilasi Terhadap Peningkatan Aktivitas Fungsional Pada Pasien Osteoarthritis Lutut. Dengan sebanyak responden 14 dengan keluhan Osteoarthritis.Responden dibagi menjadi dua kelompok yaitu, kelompok kontrol dan kelompok eksperimen. Dengan hasil uji indenpendent sample Test diperoleh nilai sebesar 0.001 sehingga dapat ditarik kesimpulan ada pengaruh traksi osilasi terhadap peningkatan aktivitas fungsional.

Hasil penelitian ini sesuai dengan penelitian yang dilakukan dengan Shahnawaz, (2018) tentang Pengaruh latihan Isometric quadriceps terhadap kekuatan otot, nyeri, dan fungsi lutut pada pasien yang mendertita Osteoarthritis, yang dilakukan pada 52 responden. Dengan Hasil penelitian pada kelompok perlakuan didapatkan peningkatan kekuatan otot, penurunan intensitas nyeri, dan meningkatkan fungsi sendi dengan latihan isometrik quadriceps pada 5 minggu ada pengaruh yang signifikan dengan grup kontrol $(p<0.05)$.

Asumsi peneliti bahwa dengan memberikan Manual Traksi dan Isometric Exercise dengan intensitas, frequensi dan waktu yang telah ditentukan sangat efektif untuk penderita Osteoarthritis Knee yang mengalami gangguan aktivitas fungsional, karena intervensi ini dapat mengurangi nyeri meningktakan kekuatan otot, luas gerak sendi sehingga aktivitas fungsional meningkat.Gerakan dari latihan Isometric Exercise sangat mudah untuk dilakukan sehingga dapat di ulang kembali di ruangan sehingga latihan setelah dari poli fisioterapi 
Received: 18 June 2021 :: Accepted: 26 June 2021 :: Published: 30 June 2021

\section{Kesimpulan}

Berdasarkan uji statistik dan pembahasan diatas maka dapat disimpulkan bahwa :

a) hasil penelitian terdapat 19 responden di Rumah Sakit Grandmed, menggambarkan bahwa pelaksanaan pemberian Manual Traksi dan Isometric Exercise pada Penderita Osteoarthritis Knee.

b) Nilai Rata - rata Aktivitas Fungsional sebelum pemberian Manual Traksi dan Isometric Exercise sebesar 22,58 dengan SD 4,635.

c) Nilai rata - rata Aktivitas Fungsional sesudah pemberian Manual Traksi dan Isometric Exercise sebesar 18,00 dengan SD 4,655.

d) Berdasarkan hasil uji statistic diperoleh nilai $p$-value $\alpha<(0,001<$ $0,05)$ dan setelah dilakukan pembahasan di atas, maka dapat disimpulkan ada pengaruh sebelum dan sesudah pemberian Manual Traksi dan Isometric Exercise terhadap peningkatan aktivitas fungsional pada penderita Osteoarthritis Knee di Rumah Sakit Grandmed Lubuk Pakam.

\section{Ucapan Terima Kasih}

1. Direktur Rumah Sakit Grandmed Lubuk Pakam yang telah mengijinkan utk melaksanakan kegiatan ini.

2. Kepada pasien yang bersedia menjadi subyek kegiatan ini.

3. Kepada Rektor Institut Medistra yang btelah mendukung pelaksanaa.

4. Seluruh pihak yang membantu penelitian ini.

\section{Daftar Pustaka}

Anisa Ika Pratiwi. (2015, Februari). Diagnosis And Trement

Osteoarthritis. JMajority,4(4),1017.http://juke.kedokteran.unila.ac .id/index.php/majority/article/view $/ 572$

Anwar (2012). Efek Penambahan RollSilde Fleksi-Ekstensi Terhadap

Penurunan Nyeri Pada

Osteoarthritis Sendi

Lutut.Universitas

Muhammadiyah Surakarta.
Arikunto. (2012). Prosedur Penelitian Suatu Pedekatan Praktek. Jakarta

Rineka Cipta

Ayling Soeryadi,Joudy Gessal,Lidwina S,Sengkey. (2017, JuliDesember). Gambaran Faktor Risiko Penderita Osteoarthritis Lutut di Instalasi

Rehabilitasi Medik RSUP Prof.Dr.R.D.Kandou Manado Periode

Januari-Juni2017.JurnaleClinic(eCI),5(2),267-273.

https://ejournal.unsrat.ac.id/index .php/eclinic/article/view/18540/18 067

Bonnell, K. L., Crossley, K .M., Cowan, S.M., dan Connell,J. (2015).Knee Flexion during stair ambulation is altered in individuals With Patellofemoral pain.

Delima Apriliana, Sella Sahruddin, Karma Ibrahim. (2017, Mei). Hubungan Instensitas Sholat,Aktivitsas Olahraga Dan Riwayat Kebiasaan Mandi Malam Dengan penyakit Osteoartrhitis Pada Lansia Di Panti Sosial

Tresna Werdha Minaula Kota Kendari Tahun 2017. JURNAL ILMIAH MAHASISWA KESEHATAN MASYARAKAT, 2(6), 1-9. https://media.neliti.com/media/pu blications/185058-ID-none.pdf

Gay,C.et al.(2016) Educating Patients About The Benefits of Physical Activity

and Exercise for Their Hip and Knee Osteoarthritis.Systematic Literature Riview, Annals of Physical and Rehabilitiation Medicine.

https://www.sciencedirect.com/sci ence/article/pii/S18770657160004 39

Hidayat, A,A. (2012). Metode Penelitian Keperawatan dan Teknik Analisa Data Jakarta : Salemba Medika

Indri Susilawati,Ketut Tirtayasa,S.Indra Lesmana. (2015, Januari ). Latihan Closed Kinetic Chain Lebih Baik Daripada Open Kinetic Chain Untuk Meningkatkan Kemampuan Fungsioanal Pada Osteoarthritis Lutut Setelah Pemberian Micro 
Received: 18 June 2021 :: Accepted: 26 June 2021 :: Published: 30 June 2021

Wave Diathermy (MWD) Dan Transcutaneus Electrical Nerves Stimulation (Tens). Sport And Fitness Journal, 3(1), 26-34. https://ojs.unud.ac.id/index.php/s port/article/view/11870

Ismail. (2013, Januari). Penambahan Traksi Translasi Pada Intervensi Ultraounds, Transcutenous

Electrikal Nerve Stimulation dan Quadriceps Exercise Lebih memperbaiki Lingkup Gerak Sendi Pada Osteoarthtitis Lutut. Jurnal Fisioterapi, 1(1). https://docplayer.info/48392050-

Penambahan-traksi-translasipada-intervensi-ultrasoundtranscutaneus-elektrikal-nervestimulation-dan-quadricepsexercise.html

Ismaningsih,Iit Selviani. (2018, Agustus ). Penatalaksanaan Fisioterapi Kasus Osteoathritis Genue Bilateral Dengan Intervensi Neuromuskuler Taping Dan Strengthening Exercise Untuk Meningkatkan Kapasitas Fungsional. Jurnal IImiah Fisioterapi (JIF), 1(02), 38-46. http://jurnal.univrab.ac.id/index.p hp/jif/article/view/569

Junaidi. (2013) Pengaruh Pemberian Terapi Osilasi Terhadap Peningkatan Aktivitas Fungsional Pada Pasien Osteoarthritis Lutut.Universitas Muhammadiyah Surakarta

Kemenkes RI. (2014). Laporan Riset Hasil Kesehatan Dasar (RISKESDAS). Jakarta

Kisner, C, . Colby, L.A. (2017) Terapi Latihan, $\mathrm{Vol} 2$ Ed 6 Judul :Kedokteran EGC Jakarta : Dwi widiarti

Meutia Maulina. (2017, Februari). Kerusakan Proteoglikan Pada Osteoartritis. Jurnal IImiah Sains, Teknologi,Sosial dan Budaya, 1(1), 61-67.

http://www.jurnal.umuslim.ac.id/i ndex.php/LTR2/article/view/525

Notoadmojo. (2014). Metode Penelitian Kesehatan. Jakarta : Rineka Cipta

Nurun Laasara. (2018, Desember). Pengaruh Latihan Isometric Quadriseps Terhadap Penurunan
Skala Nyeri \& Kekakuan Sendi

Lutut Pada Klien Osteoarthritis

Lutut Di Wilayah Puskesmas Gamping Ii Sleman Yogyakarta. Dinamika Kesehatan, 9(2), 637651.

https://ojs.dinamikakesehatan.uni sm.ac.id/index.php/dksm/articel/di download/379/329

Nursalam. (2011). Konsep dan Penerbitan Metodologi Penelitian IImu Keperawatan,Edisi 2 Jakarta : Salemba Medika

Prieharyi,Yekti Mumpuni. (2017), Ed I Deteksi Osteoarthritis vs Osteoporosis Perbedaan,Seluk buluk dan penangannya. Yogyakarta

Pusat Data dan Informasi Kementrian Kesehatn RI, 2014.Gambaran Kesehatan Lanjut Usia di Indonesia.

http://www.depkes.go.id/resource s/download/pusdatin/profilkesehatan-indonesia/profilkesehatan-indonesia-2014.pdf

Rudi.(2016). Pengukuran Skala Jette Aktivitas Fungsional Osteoarthritis.

https://www.scribd.com/doc/2011 21275/Skala-Jette

Shahnawaz Anwer,Ahmad Alghadir. (2014). Effect Of Isometric Quadriseps Exercise On Muscle Strength,Pain, And Function in Patients With Knee Osteoarthritis. J.Phys.Ther.Sci, 26(5), 745-748. https://www.ncbi.nlm.nih.gov/pmc /articles/PMC4047243/

Theresia Titin Marlina. (2015, Januari). Efektivitas Latihan Lutut Terhadap Penurunan Intensitas Nyeri Pasien Osteoarthritis Di Yogyakarta. Jurnal Keperwatan Sriwijaya, 2(1), 44-56.

https://ejournal.unsri.ac.id/index. php/jk_sriwijaya/article/view/2331

Sugiyono. (2014). Metode Penelitian Pendekatan Kuantatif Kualitatif dan $R \& D$, Bandung : Alfabeta

Sugiyono. (2016). Metode Penelitian Kuantitatif, Kualitatif, dan $R \& D$, Bandung : Alfabeta, CV

Syaifuddin. (2013). Anatomi Tubuh Manusia Untuk Mahasiswa 


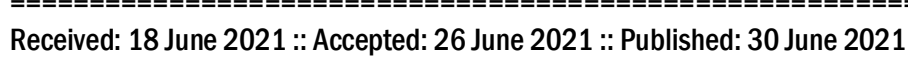

Keperawatan Jakarta : Selemba Medika

Triyana. (2015). Standar Prosedur Operasional Pemberian Traksi Oscilasi Pada Pasien Dengan Frozen Shoulder.Universitas Muhammadiyah Surakarta 